\title{
Redistributive effects of CAP liberalisation: from the sectoral level to the single farm
}

\author{
Andre Deppermann ${ }^{1,2, *}$, Frank Offermann ${ }^{3}$, Harald Grethe ${ }^{1}$ \\ ${ }^{1}$ Agricultural and Food Policy Group, University of Hohenheim, Germany \\ ${ }^{2}$ Ecosystems Services and Management Program, International Institute for Applied \\ Systems Analysis, Laxenburg, Austria \\ ${ }^{3}$ Institute of Farm Economics, Thünen Institute, Braunschweig, Germany \\ * Corresponding author: International Institute for Applied Systems Analysis, \\ Schlossplatz 1, 2361 Laxenburg, Austria, depperma@iiasa.ac.at, Tel.: +43 \\ 2236807239
}




\section{Redistributive effects of CAP liberalisation: from the sectoral level to the single farm}

Abstract. There is a growing public and political interest in effects of agricultural policy on income distribution in the agricultural sector. Most of the literature regarding redistributive effects of agricultural policy is ex-post and static in nature and many tools for an ex-ante analysis of impacts of sectoral or macroeconomic policies depict farm groups or representative farms rather than individual farms. However, the measurement of inequality is highly sensitive to the aggregation of individual data. In this paper, redistributive effects of an abolishment of different instruments of the European Common Agricultural Policy (CAP) are analysed with a tool that is able to consistently assess impacts of sectoral policy on individual farm incomes. We find that an abolishment of the main components of the CAP, direct payments and market and price policies, results in a more unequal income distribution in relative terms, but a more equal income distribution in absolute terms. Based on the latter, we conclude that if the CAP aims at a more equal income distribution within the agricultural sector, then significant scope for improving the design of respective policy instruments exists.

Keywords: farm model, market model, micro accounting, income distribution

\section{Introduction}

The last two decades of reforms of the Common Agricultural Policy (CAP) of the European Union (EU) were characterized by replacing classical market price support measures by direct payments. Moreddu (2011) argues that due to this shift, agricultural support has become more visible and consequently, the distribution of support among farmers has gained more public attention. Fittingly, the European Commission (2012, p.8) states in its annual "Report on the distribution of direct aid to farmers" that "direct payments have lost their compensatory character over time and have increasingly become a support ensuring a certain farm income stability". Increasing public interest in the distribution of agricultural support and the question 'who gets what' is reflected by general media coverage (e.g. The New Statesman, 2012) and in the specialized press (e.g. Agra-Europe, 2013, p.3). Thus, equity issues in the agricultural sector increasingly become an area of political concern, even on a national or sub-national basis. The European Commission (2012, p.8) e.g. claims that "the proposals for the CAP after 2013 [...] aim to reduce the discrepancies between the levels of payments obtained after full implementation of the current legislation, between farmers, regions and Member States”. Besides growing public and political interest, there are also good reasons to analyse the effects of agricultural policy on income distribution in the agricultural sector from an economic point of view. For instance, Mishra et al. (2009) refer to links between farm income inequality and technology adaption, productivity, sectoral growth, and social issues such as family health.

This interest is also reflected in the scientific literature. However, most of the literature regarding redistributive effects of agricultural policy is ex-post and static in nature. Several studies focus on the distribution of direct payments (e.g. Keeney, 2000; El Benni and Finger, 2013, Severini and Tantari, 2013, 2015). Fewer authors also take effects of market price support into account and aim to assess redistributive effects of the whole system of agricultural support (e.g. Allanson, 2006; 2008; Moreddu, 2011). Yet, despite the undoubted usefulness and importance of ex-post analyses, they are of limited use when it comes to the evaluation of distributional impacts of policies that do not currently exist, but that 
might exist in the future. For such an exercise counterfactual situations have to be constructed, at best accounting for incentive effects and the behaviour of individuals (Bourguignon and Ferreira, 2003).

Simulation models account for behavioural effects. But most macro or sectoral models apply representative groups rather than individual income units and the measurement of inequality is highly sensitive to the aggregation of individual data. Consider a population being divided into $k$ mutually exclusive groups and $I^{\text {total }}$ representing an additively decomposable ${ }^{1}$ income inequality index of the form: $I^{\text {total }}=I^{\text {within }+} I^{\text {between }}$ with $I^{\text {within }}$ representing a (weighted) sum of income inequality inside the $k$ groups and $I^{\text {between }}$ the inequality between subpopulation means (Deutsch and Silber, 1999). In the extreme case of just one representative group all the desired information would be hidden in $I^{\text {within }}$ whereas only $I^{\text {between }}$ would be measurable, but without any meaning in this case. Obviously, inequality inside of aggregated groups is not observable and thus, the loss of information generates a downward bias in the measurement of overall inequality by only incorporating grouped income data. Even the assumption of an exogenous constant degree of inequality within the groups and the application of group specific changes in average income to all group members is likely to produce biased results because there is no reason why withingroup income distribution should be unaffected by different scenario assumptions (Bourguignon et al., 2005; Savard, 2005). The share of inequality that is accounted for by the between-groups component is expected to increase with the number of subgroups of a population, other factors being equal (Shorrocks and Wan, 2005).

In other scientific areas, e.g. poverty analysis or tax reform analysis, it is quite common to conduct exante assessments of macroeconomic shocks on individual income distributions on a national level. To this end, methods were developed to commonly assess impacts of macroeconomic shocks on an aggregate and individual level by combining outputs of macro models with individual data, mostly large population or household surveys (e.g. Debowicz and Golan, 2013, Cororaton and Cockburn, 2007).

Only a few similar tools for the measurement of impacts of sectoral or macroeconomic policies on the individual farm income level exist for the agricultural sector. Keeney and Beckman (2009), Keeney (2009), and Hertel et al. (2007), e.g. combine a computable general equilibrium (CGE) model with a large farm household survey to assess distributional effects of WTO negotiations on US agricultural households. Louhichi and Valin (2012) combine a CGE model with a programming model that depicts individual arable farms in France to estimate impacts of biofuel policies.

Several other tools exist for ex-ante policy impact analyses in the agricultural sector, which depict farms at regional or farm type level but not at the individual level. The CAPRI model for example is applied to estimate farm type specific income effects of reforms of EU direct payments (Gocht et al., 2013). Deppermann et al. (2014) conduct an analysis of agricultural policy reform induced redistributive effects for the western German agricultural sector based on 467 farm groups. These attempts already apply quite disaggregated models. However, it is not clear how serious the grouping of individual data affects the results of an analysis of redistributive effects.

Against this background the main objectives of this paper are (1) to analyse the distributional impacts of an abolishment of different CAP instruments with a tool that is able to consistently assess impacts of sectoral policy on individual farm incomes, (2) to derive conclusions regarding the policy implications of

\footnotetext{
${ }^{1}$ The term 'additively decomposable' refers to the property of an inequality index, to be subgroup decomposable into exactly two terms: the between-groups inequality component which is gained by replacing all individual incomes by subgroup means and the within-group component, which is a weighted average of inequality within subgroups. The Gini coefficient e.g. is not additively decomposable in this sense (Deutsch and Silber, 1999).
} 
the analysis, and (3) to get insights into the effects of grouping individual data with regard to the analysis of redistributive effects.

\section{Modelling chain}

\subsection{Description of the overall model chain}

Measuring redistributive effects of agricultural policy reforms requires a simultaneous analysis of impacts at different levels of aggregation. Effects at the sectoral level need to be taken into account and at the same time information on individual production and income changes at the micro level is necessary to catch the full impact on income distribution.

In this study, a modelling system consisting of three different single models depicting three different levels of aggregation is developed to consistently measure changes in individual incomes among western German farms resulting from agricultural policy reforms. Figure 1 presents a schematic overview of the model chain.

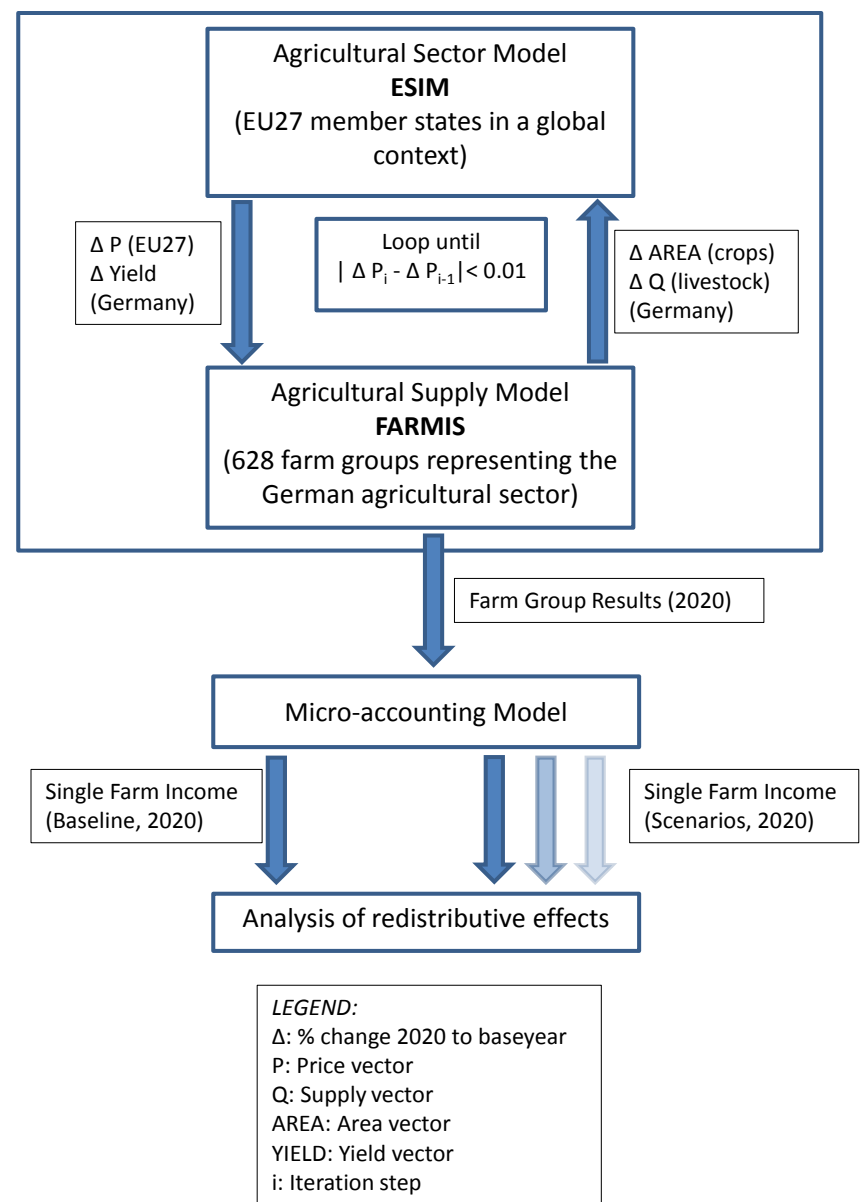

Figure 1: Methodological framework for an ex-ante measurement of redistributive effects of agricultural policies on farm incomes

Source: Own composition on the basis of Mussard and Savard (2010). 
The model with the highest level of aggregation is an agricultural sector model depicting European agricultural markets in detail and the agricultural sector of rest of the world in a more aggregate manner. It is a partial model in the sense that it explicitly models the agricultural sector and takes all other sectors as exogenously given. Thus, core macroeconomic variables such as inflation rates and GDP growth rates are exogenous to the model. At the meso-level, a model which depicts the supply side of the German agricultural sector in great detail is applied to measure impacts of agricultural policy changes on 628 heterogeneous farm groups. Both simulation models are two already pre-existing large scale models, the European Simulation Model (ESIM; Grethe, 2012) at the sectoral and the Farm Modelling Information System (FARMIS; Osterburg et al., 2001; Bertelsmeier, 2005; Offermann et al., 2005) at the farm group level. They both have been combined in previous studies to measure the impact of agricultural policy on income distribution, however, on the basis of farm groups rather than individual farm incomes (Deppermann et al., 2014). The models are coupled in an iterative way until they converge on exchanged variables in the analysis of a joint scenario (Deppermann et al., 2010).

After convergence between ESIM and FARMIS is achieved, farm group results are passed in a top-down manner to a newly developed micro model to assess individual farm incomes for the year 2020, the final year of the simulation period. The micro model is an accounting model in the sense of Bourguignon et al. (2008), i.e. without own behavioural component. It further disaggregates the results of the farm groups commonly calculated by ESIM and FARMIS. The micro model serves as an add-on to the FARMIS model, since it relies on its structure. It is based on the German farm accountancy data network (FADN).

With this modelling system, ex-ante evaluations of policy scenarios are conducted. Based on simulation results for the year 2020 income distribution indices are calculated. To evaluate the state of income inequality in the agricultural sector and the degree of progressivity of different reform packages, inequality indices of different policy scenarios are compared to a reference scenario.

\subsection{From the sectoral to the meso-level: an iterative approach}

The modelling system covering the sectoral and the meso-level is described in more detail in Deppermann et al. (2010). The linkage of the two models allows us to quantify adjustment processes both at the sectoral level and at the farm group level for the German agricultural sector. Below, the two models and their interface are briefly presented.

ESIM (Grethe, 2012) is a comparative-static, net-trade, partial equilibrium model of the European agricultural sector. It depicts the EU-27 at the member state level with a strong focus on the CAP. In addition, ESIM also models the highly aggregated rest of the world. ESIM contains 31 regions and 47 products as well as a high degree of detail for EU policy including specific and ad valorem tariffs, tariff rate quotas, intervention and threshold prices, export subsidies, coupled and decoupled direct payments, production quotas, and set-aside regulations. All behavioural functions (except for sugar supply) in ESIM are isoelastic. ESIM has a very detailed depiction of the complex system of substitution of land among different products and the relationship between ruminant production and agricultural area. The price formation mechanism in ESIM assumes an EU point market for all products except for non-tradables, for which the price results from a domestic supply and demand market clearing equilibrium at the EU member state level.

FARMIS is a comparative-static process-analytical programming model for farm groups (Osterburg et al., 2001; Bertelsmeier, 2005; Offermann et al., 2005). Production is differentiated for 27 crop and 15 
livestock activities. The matrix restrictions cover the areas of feeding (energy and nutrient requirements, calibrated feed rations), intermediate use of young livestock, fertilizer use (organic and mineral), labour (seasonally differentiated), crop rotations and political instruments (e.g., set-aside and quotas). The model specification is based on information from the German farm accountancy data network, supplemented by data from farm management manuals. Data from three consecutive accounting years is averaged to reduce the influence of yearly variations common in agriculture (e.g., due to weather conditions) on model specification and income levels. Key characteristics of FARMIS are: 1) the use of aggregation factors that allow for representation of the sectors' production and income indicators; 2) input-output coefficients which are consistent with information from farm accounts; and 3) the use of a positive mathematical programming procedure to calibrate the model to the observed base year levels. Prices are generally exogenous and are provided by market models. An exception to this applies to specific agricultural production factors, such as the milk quota, land, and young livestock, where (simplified) markets are modelled endogenously, allowing the derivation of respective equilibrium prices under different policy scenarios. FARMIS uses farm groups rather than single farms not only to ensure the confidentiality of individual farm data, but also to increase manageability and the robustness of the model system when dealing with data errors that may exist in individual cases. Homogenous farm groups are generated by the aggregation of single farm data. For this study, farms were stratified by region, type, and size, resulting in 628 farm groups which represent the German agricultural sector, of which 467 are located in western Germany.

ESIM and FARMIS were linked through the exchange of solution variables (vectors of price and yield changes from ESIM to FARMIS and vectors of quantity changes from FARMIS to ESIM) until both models converged on these variables in the analysis of joint scenarios. Convergence is defined to be reached when the difference in price and area (supply for livestock) changes less than $1 \%$ between two iteration steps. Before this final and rather mechanical procedure was pursued, considerable preparatory work was undertaken. Policy parameters and assumptions as well as a wide range of further parameters exogenous to both models were harmonized, including inflation rates, technical progress and changes of factor costs. Consistent product interfaces were defined and for a first stand-alone baseline scenario, vectors of price and yield changes were created by ESIM and implemented (as exogenous variables) into FARMIS. Afterwards, a detailed comparison and analysis of the reaction of both models to the same vector of price changes and subsequent model modifications concerning the area allocation for crops as well as the supply of livestock products were conducted. Finally, the iteration process was carried out and thus in effect, the German supply component in ESIM was replaced by FARMIS.

The above described modelling system is calibrated to a base period (average of the years 2006-2008). The baseline (the reference scenario) and reform scenarios are conducted for the year 2020. Scenarios are evaluated in comparison to the baseline scenario and thus provide a comparative-static analysis of exogenous policy changes.

\subsection{From the meso to the micro-level: a top-down approach with micro accounting}

After ESIM and FARMIS converged in the first step of the modelling chain, detailed results regarding production patterns, factor demand and income sources for 628 farm groups are obtained representing the whole German agricultural sector. This information is further disaggregated by a microsimulation model which is integrated into the modelling system (Figure 1). In the following sections at first the choice of the methodology, the income variable under consideration, and the choice of the study area are explained before the model is introduced in detail. 
FARMIS applies farm groups instead of individual farms due to better manageability and an increased robustness of the model. Especially potential data errors in individual cases could lead to high variations among the calculated input-output coefficients between farms and result in higher solution instability (Osterburg et al. 2001). Furthermore, the time needed to set up the model with an updated database (which would likely be longer with the implementation of individual farms) has to be taken into account. Aggregation however comes at a cost. Firstly, there is the possibility of aggregation bias, which occurs when the aggregated outcome of model solutions for individual farms differs from the model solution for the respective aggregated farm. For linear programming models, Day (1963) shows that exact aggregation can be obtained if aggregated farms exhibit technical, pecunious and institutional homogeneity. In practical applications, these requirements can hardly be fully met, but aggregation bias is usually reduced by clustering farms by criteria which are related to these requirements (like region, size, etc; Hazell and Norton, 1986). Secondly, the aggregation of farms can mask the heterogeneity of result indicators. For the measurement of inequality, which has not been a traditional field of analysis for the FARMIS model, the respective clustering criteria do not ensure homogeneity with respect to some of the variables important for the inequality analysis (e.g., information on ownership of used resources), and a certain part of inequality will be hidden inside the groups and thus not be observable.

For this study it was decided that the two large scale models at the top of the modelling chain shall be kept exercisable as stand-alone models. This has the advantage that updated versions of the single models can easily be implemented in the modelling chain. This rather practical choice relates to the institutional challenge of sustainable maintenance of linked model systems, which is a matter of sufficient financial and/or human resources (Offermann, 2008). Hence, to make use of synergy effects in model development it was decided to run the FARMIS model based on farm groups and develop an add-on model that allows a further disaggregation of the grouped results instead of directly running FARMIS with individual farms. The microsimulation model itself can easily be switched to an updated model database.

The indicator applied for the measurement of income inequality among farms in the German agricultural sector is family farm income (FFI). FFI provides information on the return to land, labour, and capital resources owned by the farm family, as well as the remuneration of entrepreneurial risk. Henceforth, the terms income and FFI will be used synonymously. Due to the dominance of corporate farms in eastern Germany all analyses presented in this study are restricted to 467 western German farm groups aggregated from 8034 individual farms, because no comparability between different farm structures could be ensured when using FFI as an indicator.

For the base period both individual and grouped data can be observed and thus, the information on inequality which is lost due to data grouping and working with average values instead of micro data can be calculated. For the current base data of the modelling system, a comparison of the relative Gini coefficient reveals some differences in inequality for the base period: the relative Gini coefficient of single farm income data is 0.55 and the relative Gini coefficient of farm group income data is 0.40.

The objective of the microsimulation model is the disaggregation of farm group results of the last year of the simulation period. Individual FFI data are generated by tracing back farm group results to the individual farms which were used for the generation of farm groups in the base year. The basic idea of the model is to calculate base year values of the shares each single production activity contributes to individual farm gross margin and resource requirements, and then adapt these proportionally according to respective farm group changes between the base year and 2020. This procedure is described in more detail in the following. 
Grouping individual FADN data for utilization in the FARMIS model implies the calculation of average production quantities, factor costs, gross margins and income values as well as the generation of aggregation factors to represent the respective proportion of the total population for each farm group in the base period. These values are subsequently applied in the FARMIS model to run simulations. Gross margins for single production activities refer to market revenues plus subsidies less attributable production costs for a specific activity and are not directly apparent in FADN data ${ }^{2}$. However, since this information is crucial for running simulations with FARMIS, several assumptions and additional calculations are made to generate activity specific gross margins, when defining the farm group programming models (for details see Offermann at al., 2005 and Osterburg et al., 2001).

Taking into account costs for resources not owned by the farm family, the income generated from considered agricultural activities is derived as:

$$
\text { Income_Agr } r_{n}^{\text {Groups }}=\sum_{i} p_{n i}^{\text {Groups }} \times q_{n i}^{\text {Groups }}-\sum_{j} c_{n j}^{\text {Groups }} \times r_{n j}^{\text {Groups }} \quad \forall n
$$

with $p_{n i}$ depicting the gross margins of commodity $i$ for farm group $n, q_{n i}$ the respective activity levels, $c_{n j}$ factor prices of land and labour and $r_{n j}$ the respective quantities of purchased factors. The index Groups is added to point out that the indicators refer to farm groups rather than individual farms. Since not all commodities, income sources and costs indicated in the German FADN are also allocated to activities and included in FARMIS (e.g., forestry and agri-tourism are not explicitly covered in the model), a part of the original FFI is not accounted for by the model and is assumed to remain fixed at base year values. This fixed income component is derived as the difference between observed FFI and calculated income from agriculture as:

$$
\text { Income_Fix } n_{n}^{\text {Groups }}=F F I_{n}^{\text {Groups }}-\text { Income_Agr }{ }_{n}^{\text {Groups }}
$$

In a next step, base year income from agriculture of individual farms is calculated. To this end farm individual activity levels from FADN data are combined with respective average gross margins which were calculated for FARMIS groups, thus reflecting the shares that single production activities contribute to the individual farm income. This is indicated in equation (3) by differentiation between individual farms (indiv) and the Groups individual farms $k$ are assigned to. Furthermore, individual costs for hired labour and rented land are as well separately calculated by utilizing average group prices and individual input quantities. The latter depend on farm specific activity levels $q$ and factor endowments $b$,

$$
\text { Income_Agr }{ }_{k}^{\text {indiv }}=\sum_{i} p_{k i}^{\text {Groups }} \times q_{k i}^{\text {indiv }}-\sum_{j} c_{k j}^{\text {Groups }} \times\left(A_{i j}^{\text {Group }} q_{k i}^{\text {indiv }}-b_{k j}^{\text {indiv }}\right) \quad \forall k
$$

where $A_{i j}$ is the matrix of resource requirements of the production activities.

Similar to the approach at group level, the part of income not covered by the model is derived as the difference between observed FFI and calculated income from agriculture as:

$$
\text { Income_Fix } x_{k}^{\text {indiv }}=F_{k} I_{k}^{\text {indiv }}-\text { Income } \_A g r_{k}^{\text {indiv }} \text {. }
$$

By running the ESIM-FARMIS modelling chain, farm group results for the year 2020 are generated. The generated changes of activity levels between the base year and the year 2020 are applied to individual base year levels. That is, all individual farms covered by a specific farm group have the same percentage

\footnotetext{
${ }^{2}$ For example, variable input costs are not directly attributed to production activities in the German FADN.
} 
changes in production. The quantity of rented land is calculated according to new farm specific crop activity levels less the farm owned share of land. Labour requirements are calculated regarding new production quantities, and hired labour costs are derived taking into account individual farm resources of family workers. Adjusted activity levels and resource requirements then are multiplied by respective gross margins and factor prices for the year 2020. This is depicted in equation (5) by differentiation between indicators referring to the base year (base) and to 2020 .

$$
\begin{aligned}
& F F I_{k}^{\text {indiv }, 2020}=\sum_{i} p_{k i}^{\text {Groups, } 2020} \times q_{k i}^{\text {indiv,base }} \times \frac{q_{k i}^{\text {Groups }, 2020}}{q_{k i}^{\text {Groups }, \text { ase }}}-\sum_{j} c_{k j}^{\text {Groups }, 2020} \times\left(A_{i j}^{\text {Groups }} q_{k i}^{\text {indiv,2020 }}-b_{k j}^{\text {indiv }}\right) \\
& + \text { Income_Fix } x_{k}^{\text {indiv }} \quad \forall k .
\end{aligned}
$$

The fixed income component is then added to the income from agriculture.

The micro-model is of the micro accounting type in the sense of Bourguignon et al. (2008) since the model is static which means there is no behaviour depicted in the model itself. A similar approach for the generation of farm incomes at the micro level is used in the FES model (Woltjer et al., 2011) which applies exogenous price changes to static single farms.

Our approach still relies on the assumption that all farmers in one group react in the same proportional way when adapting their production patterns to new price incentives. However, heterogeneity among production patterns of farms in the same group is taken into consideration because different commodities might face different price changes. The application of 467 behavioural farm groups which, on average, aggregate just 17 farms also distinguishes the modelling chain from a similar methodology presented in Keeney and Beckman (2009), Keeney (2009), and Hertel et al. (2007), which, in a nutshell, maps quantities and prices resulting from only one regional household of a CGE model to a disaggregated farm household survey.

However, one caveat remains. The overall farm population of western Germany represented by the national FADN consist of 200,000 farms in the base year. This in turn means that 8,024 FADN farms still account for only a fraction of all farms and have to be weighted by an aggregation factor to represent their respective proportion of the overall population. Thus, an implicit assumption is that one single farm depicted in the modelling system (or in the FADN data) on average represents 25 farms of the overall population in the base year.

Summing up, the model accounts for heterogeneity of farms inside a group to allow for measuring changes in inside-group inequality. Results are disaggregated in a static, top-down manner, after the ESIM-FARMIS model chain is solved. In principle, the approach is comparable to other standard micro accounting approaches utilizing representative groups. However, this analysis refers to 467 representative farm groups from a behavioural model, which in comparison is an outstandingly high number.

\section{Measurement of redistributive effects}

For the evaluation of redistributive impacts a methodology is utilized which originally was developed for the analysis of traditional redistributive policies such as tax policies (Kakwani, 1986) and has been applied for the assessment of redistributive effects of agricultural policy in several studies (e.g. Allanson, 2006, 2008, Deppermann et al., 2014). Following Kakwani’s (1986) methodology, the overall effect of redistribution of agricultural policy reforms $R$ can be measured as the difference between the relative Gini 
index ${ }^{3}$ of the baseline scenario in $2020\left(G_{x}\right)$ and the relative Gini index of the liberalisation scenario in $2020\left(G_{y}\right)$ and can be split up into a vertical component $V$ and a re-ranking component $H$ :

$R=G_{x}-G_{y}=\left(G_{x}-C_{y}\right)+\left(C_{y}-G_{y}\right)=V+H$.

The index of vertical redistribution $V$ equals the difference between the relative Gini index of the baseline situation and the relative concentration index of the liberalisation scenario $C_{y}$. The latter measures relative inequality among individual incomes after liberalisation while keeping constant the ranks which individuals had in the income parade of the baseline scenario. ${ }^{4}$ Thus, if all farms keep their baseline ranks after liberalisation $C_{y}$ and $G_{y}$ will coincide. The vertical component is determined by the state of progressivity of burden $P$ and the share of average burden in average baseline income $s$ and can also be expressed as $V=G_{x}-C_{y}=P(s /(1-s))$. Progressivity is measured by the Kakwani (1977) measure of progressivity $P=C_{B}-G_{x}$, with $C_{B}$ being the concentration index of burden which depicts the distribution of the burden ranked by baseline income. Thus, $P$ indicates to which extent a burden (i.e. income losses due to liberalisation) is distributed more unequally or equally than income in the baseline scenario (Aronson et al., 1994).

However, when farms change their ranks due to liberalisation the new state of inequality will be overestimated if only vertical effects are taken into consideration (Lambert, 2001). The vertical index treats high-income farms as high-income farms and low-income farms as low-income farms, even though they might have changed ranks due to liberalisation, i.e. farms with former high ranks in the income parade hold low ranks after liberalisation and vice versa. These re-ranking effects are identified by the index $H$, which is also known as the Atkinson-Plotnik-index of re-ranking (Atkinson, 1980; Plotnick, 1981).

So far, the measurement of redistributive effects was discussed with regard to relative inequality. Relative inequality indices are scale invariant, i.e. proportional changes in all incomes do not affect the degree of inequality. To additionally reflect another normative view of inequality equivalence, the analysis also is conducted based on absolute Gini and concentration indices which are invariant to equal absolute changes in all incomes. Absolute Gini and concentration indices can be obtained by multiplication of the relative indices by average sample incomes. In absolute terms the overall effect of redistribution can be decomposed in a similar way like the relative index above (Allanson, 2008):

$$
A R=A G_{x}-A G_{y}=\mu_{x} G_{x}-\mu_{y} G_{y}=\left(\mu_{x} G_{x}-\mu_{y} C_{y}\right)+\left(\mu_{y} C_{y}-\mu_{y} G_{y}\right)=A V+A H
$$

where A indicates the absolute versions of the respective indices and $\mu_{x}$ and $\mu_{y}$ represent the average income of the baseline and the scenario results, respectively. Since an equal absolute burden would be assessed as distribution neutral it is the benchmark for the measurement of progressivity in absolute terms. Thus, the (relative) concentration index of burden $\left(C_{B}\right)$ indicates whether a burden is progressively or regressively distributed since it is negative (positive) when small incomes have to bear a greater (smaller) part of the burden than higher incomes.

\footnotetext{
3 The relative Gini index $(G)$ can (in discrete form) be specified as: $G=\left(\frac{1}{2 n^{2}} \sum_{i=1}^{n} \sum_{j=1}^{n}\left|y_{i}-y_{j}\right|\right) / \mu$ with $y_{i}$ representing the income of individual $i(i=1,2,3, \ldots, n)$ and $\mu$ average income (e.g. Pyatt, 1976).

${ }^{4}$ The corresponding Lorenz curve of a Gini index plots cumulative shares of one variable against cumulative shares of units of observation which are ranked in ascending order with regard to the same variable. Respectively, the corresponding concentration curve of a concentration index plots cumulative shares of one variable against cumulative shares of units of observation which are ranked according to another variable (Lambert, 2001).
} 
The absolute and relative analyses may lead to oppositional results. For the same scenario a burden may be assessed as progressive in absolute terms (indicated by a positive $C_{B}$ ) but as regressive in relative terms (indicated by a negative $P$ if $C_{B}<G_{x}$ ) due to different benchmarks of distributional neutrality (Allanson and Petrie, 2012).

Liberalising the agricultural sector has clear negative impacts on average farm income in the presented scenarios with considerable shares of the sample having negative incomes after liberalisation. The appearance of negative incomes in general is unproblematic for the absolute Gini. However, even though the relative Gini coefficient is well defined for negative incomes as well (Amiel et al, 1996; Cowell, 2009), some difficulties may arise in interpretation of its results, e.g. it is argued that inequality may be overestimated in such a case (Chen et al, 1982). Recalling that average distances among individual incomes appear in the numerator of the relative Gini and mean income in the denominator (footnote 3, it becomes clear that the relative Gini increases exponentially with decreasing mean income, assuming that absolute distances between income units do not change. This is true also when negative incomes are excluded. However, the appearance of negative incomes makes this effect more pronounced because it increases the spread between numerator and denominator without having a 'natural bound': absolute average distances can be kept constant and at the same time mean income can become close to zero ${ }^{5}$. Therefore, the relative Gini is no longer bound to the maximum value of one. Vice versa, with the allowance for negative incomes absolute average distances can increase without a 'natural bound' while keeping mean income constant. If this happens with an already comparatively low mean income, changes in absolute distances may seem disproportionally strong in relative terms.

\section{Scenarios}

With the above described modelling system, scenarios are conducted for the year 2020 with the model base period being an average of the years 2006-2008. Three different liberalisation scenarios are compared with a reference scenario (the baseline) regarding their income distribution. In the baseline, the 2003 Reform and the Health Check of the CAP are fully implemented except for the abolishment of milk quotas. Milk quotas are assumed to increase until 2015 according to the Agenda 2000 decision, including the additional 2\% quota increase in 2008 and the fat adjustment in 2009/10. It is assumed that a (first generation) biofuel share of $8 \%$ in total EU transport fuel consumption will be reached by 2020 . Furthermore, the sugar market reform decided upon in 2005 is implemented and set-aside obligations are removed in 2008. The baseline adopts constant levels of tariffs, export subsidies, tariff rate quotas (except for sugar), and the current system of intervention prices. For the international environment, ESIM is calibrated to FAPRI world market price projections (FAPRI, 2011) and no changes in external trade policies of the EU are assumed until 2020.

To account for the effects of liberalising agricultural policy on income in the agricultural sector, the baseline results in 2020 are compared with results of other scenarios in 2020. The single scenario results reflect impacts of different, exogenously defined policy changes on the income distribution compared to the baseline scenario. The strongest liberalisation scenario assumes a full market liberalisation of EU agricultural policies (i.e., the abolishment of all intervention prices, tariffs, quotas, subsidies, and direct payments). Therefore, in 2020 the EU price level equals the world market price for tradable products. In another scenario isolated effects of a separate abolishment of direct payments (DP) are analysed

\footnotetext{
${ }^{5}$ Of course mean income can become negative as well, which would result in a negative value for the relative Gini. However, we abstract from this possibility here since the discussion of negative Ginis is beyond the scope of this paper and not relevant in the empirical analysis.
} 
(henceforth, No_DP scenario) and in another scenario all price policies are abolished (henceforth, No_Pricepol scenario), but direct payments are still paid to farmers to single out the effects of different policy instruments.

\section{Results}

In this chapter distributional effects of different scenarios are presented. Results are calculated based on 8034 individual farm data on the one hand and on 467 FARMIS groups on the other hand to evaluate the aggregation error which appears when distributional impacts are accounted for by the application of grouped data.

General inequality effects will at first be discussed on the basis of individual data, followed by comparison to results based on grouped data and discussion of emerging differences.

In the No_DP scenario income is reduced by 8,953€ on average, which accounts for $19.7 \%$ of income in the baseline scenario (Table 1$)^{6}$. This comparatively moderate effect ${ }^{7}$ partly is due to the high rate of capitalisation of DPs in land prices assumed in FARMIS and the high share of rented land in western Germany (68\%, on average, in the baseline scenario in $2020^{8}$ ).

In absolute terms the DP cut leads to a slightly more equal situation. Little re-ranking effects occur and the overall redistributive effect also is small, which is due to the moderate average support reduction and due to a comparatively low level of progressivity of income losses. Yet, the $C_{B}$ measure indicates that support reduction is progressively distributed which means that higher incomes bear a higher burden of an abolishment of DPs than smaller incomes do. In tendency, absolute losses increase with the income levels. The relative analysis reveals an opposite inequality effect: Inequality in relative terms increases after the abolishment of DPs and the negative index of progressivity $P$ indicates a regressive distribution of losses. This means that relative to baseline results, lower income farms tend to lose larger shares of their incomes than farms with higher incomes.

In the No_Pricepol scenario (Table 1, Section III) income cuts are more pronounced compared to the No_DP scenario. On the one hand, losses in the No_DP scenario are low because of the capitalisation effects in the land market and on the other hand, losses are high in the No_Pricepol scenario, mostly due to the abolishment of high tariffs and export subsidies in the livestock sector. Furthermore, the milk and sugar markets are heavily affected due to the removal of quota restrictions and relatively high border protection. Thus, income on average is reduced by $48 \%$ when price policies are abolished. However, such results should be interpreted against the background that with this strong reduction in average income, significant structural change such as an increase in farm size and farmers leaving the sector can be expected which is not depicted in current model specifications.

\footnotetext{
${ }^{6}$ Results presented in this paper slightly differ from those presented in Deppermann et al. (2014) for the analysis based on grouped data due to some minor changes undertaken in the modeling system. However, variations are very small and do not affect any conclusion drawn from the analysis.

${ }^{7}$ Average losses of DPs account for 18,331€.

${ }^{8}$ It shall be noted that in the FADN very small farms with less than 16 European Size Units are excluded for the years of our model base period. Thus, the share of rented land in the farms covered by the models is a bit higher than for all farms, since very small farms usually operate with a higher share of own land.
} 
In absolute terms, the No_Pricepol scenario clearly leads to a positive overall effect of redistribution. Similar to the No_DP scenario, higher income farms tend to bear higher absolute losses than lower income farms. The higher $C_{B}$ index indicates that the distribution of losses is even more unfavourable for higher income farms than in the No_DP scenario. In relative terms, income inequality increases compared to baseline values. However, almost half of the overall effect originates from re-ranking effects. The index of progressivity is clearly negative, which indicates that lower income farms bear a larger share of the overall burden than their share in baseline income. 
Table 1: Decomposition of changes in income inequality (individual data vs. grouped data)

\begin{tabular}{|c|c|c|c|c|c|}
\hline & & \multicolumn{2}{|c|}{ Relative analysis } & \multicolumn{2}{|c|}{ Absolute analysis } \\
\hline & & Individual data & Grouped Data & Individual data & Grouped Data \\
\hline \multicolumn{6}{|l|}{ I) Baseline Results } \\
\hline Average income (in $€$ ) & \multirow[b]{2}{*}{$\begin{array}{l}\text { (A) } \\
G_{x}\end{array}$} & \multicolumn{4}{|c|}{45,424} \\
\hline Gini index of income & & 0.560 & 0.422 & 25,443 & 19,164 \\
\hline \multicolumn{6}{|l|}{ II) No_DP scenario } \\
\hline $\begin{array}{l}\text { Average income (in } € \text { ) } \\
\text { Average support reduction (in } € \text { ) } \\
\text { Average rate of reduced support } \\
\text { (support reduction/base income) }\end{array}$ & S & & & $\begin{array}{l}470 \\
53 \\
97\end{array}$ & \\
\hline Gini index & $\begin{array}{l}\text { (A) } \\
\mathrm{G}_{y}\end{array}$ & 0.662 & 0.487 & 24,155 & 17,775 \\
\hline Concentration index & (A) $\mathrm{C}_{\mathrm{y}}$ & 0.649 & 0.480 & 23,662 & 17,496 \\
\hline Total redistributive effect & (A) $\mathrm{R}$ & -0.102 & -0.065 & 1,288 & 1,389 \\
\hline Index of re-ranking & (A) $\mathrm{H}$ & -0.014 & -0.008 & -493 & -279 \\
\hline Index of vertical equity & (A) $\mathrm{V}$ & -0.089 & -0.058 & 1,781 & 1,668 \\
\hline $\begin{array}{l}\text { Index of progressivity of support } \\
\text { reduction }\end{array}$ & $\mathrm{P} ; \mathrm{C}_{\mathrm{B}}$ & -0.361 & -0.236 & 0.199 & 0.186 \\
\hline \multicolumn{6}{|l|}{ III) No_Pricepol scenario } \\
\hline Average income (in $€$ ) & & \multirow{2}{*}{\multicolumn{4}{|c|}{23,823}} \\
\hline Average support reduction (in €) & & \multicolumn{2}{|c|}{21,601} & & \\
\hline $\begin{array}{l}\text { Average rate of reduced support } \\
\text { (support reduction/base income) }\end{array}$ & S & \multicolumn{4}{|c|}{0.476} \\
\hline Gini index & $\begin{array}{l}\text { (A) } \\
\mathrm{G}_{\mathrm{y}}\end{array}$ & 0.782 & 0.498 & 18,632 & 11,857 \\
\hline Concentration index & (A) $\mathrm{C}_{\mathrm{y}}$ & 0.683 & 0.434 & 16,265 & 10,349 \\
\hline Total redistributive effect & (A) $\mathrm{R}$ & -0.222 & -0.076 & 6,811 & 7,308 \\
\hline Index of re-ranking & (A) $\mathrm{H}$ & -0.099 & -0.063 & $-2,367$ & $-1,508$ \\
\hline Index of vertical equity & (A) $\mathrm{V}$ & -0.123 & -0.013 & 9,178 & 8,815 \\
\hline $\begin{array}{l}\text { Index of progressivity of support } \\
\text { reduction }\end{array}$ & $\mathrm{P} ; \mathrm{C}_{\mathrm{B}}$ & -0.135 & -0.014 & 0.425 & 0.408 \\
\hline \multicolumn{6}{|l|}{ IV) Full_Lib scenario } \\
\hline Average income (in €) & & \multicolumn{4}{|c|}{14,046} \\
\hline Average support reduction (in €) & & \multicolumn{4}{|c|}{31,378} \\
\hline $\begin{array}{l}\text { Average rate of reduced support } \\
\text { (support reduction/base income) }\end{array}$ & $S$ & \multicolumn{4}{|c|}{0.691} \\
\hline Gini index & $\begin{array}{l}\text { (A) } \\
G_{y}\end{array}$ & 1.256 & 0.739 & 17,642 & 10,377 \\
\hline Concentration index & (A) $\mathrm{C}_{\mathrm{y}}$ & 1.005 & 0.582 & 14,111 & 8,179 \\
\hline Total redistributive effect & (A) $\mathrm{R}$ & -0.696 & -0.317 & 7,801 & 8,787 \\
\hline Index of re-ranking & (A) $\mathrm{H}$ & -0.251 & -0.156 & $-3,531$ & $-2,198$ \\
\hline Index of vertical equity & (A) $\mathrm{V}$ & -0.445 & -0.160 & 11,331 & 10,985 \\
\hline $\begin{array}{l}\text { Index of progressivity of support } \\
\text { reduction }\end{array}$ & $\mathrm{P} ; \mathrm{CB}_{\mathrm{B}}$ & -0.199 & -0.072 & 0.361 & 0.350 \\
\hline
\end{tabular}

Source: Own calculations. 
The Full_Lib scenario represents a combination of the No_DP and No_Pricepol scenarios. Since effects go into the same direction in both single scenarios, redistributive effects are more pronounced in the Full_Lib scenario and the state of progressivity is intermediate. The more than proportionally strong reaction of $R$ in the relative analysis partly goes back to a high share of negative incomes in the income distribution.

Comparing the analysis which is based on individual data and the one which is based on FARMIS groups it can be observed that single indicators clearly differ in terms of magnitude (Table 1). However, the direction of inequality effects and the evaluation of policy reforms are similar.

It is intuitive that both, absolute and relative Gini indices are larger when calculated on the basis of individual data since within-group inequality is additionally included in the analysis. For baseline results between-groups inequality accounts for $75 \%$ of total inequality measured on individual basis while for the Full_Lib scenario between-groups inequality only covers 59\% of total inequality.

As the farm groups are not organized according to FFI, but according to farm type, region, and size the ranking of incomes in the individual approach is different from ranking individuals due to the average incomes of their groups, which is implicitly the ranking in the grouped data approach. After the disaggregation of grouped results, some farms with low or high incomes formerly belonging to middle class income groups therefore move to the fringe of the overall distribution while contrarily high (low) income farms of low (high) income groups surge to the middle of the distribution. As a result of this reranking, average income in the baseline is 3\% lower in the lowest decile group and $7 \%$ higher in the top decile group when individual rankings are considered.

In each scenario the overall redistributive effect is more unequalizing in case of the relative Gini and less equalizing in absolute terms when calculated on the basis of individual data. The vertical effect in absolute terms is more equalizing for all scenarios. This reflects the higher degree of progressivity $\left(C_{B}\right)$ which appears because in the disaggregated version farms in the top decile have a higher income, on average, compared to the grouped data approach and tend to lose higher absolute amounts of income due to liberalisation. But then more equalizing vertical effects in the disaggregated approach are overcompensated by also higher re-ranking effects. In relative terms both, $V$ and $H$ are more negative in all scenarios.

However, redistributive effects differ only slightly in the absolute analysis. Especially the $C_{B}$ indices, which also determine the absolute vertical effects, are close between the approaches. For the relative analysis differences are higher between the two approaches. This is comprehensible given the similar degree of distribution of absolute losses after disaggregation because for the calculation of relative progressivity it is compared with the higher degree of inequality in baseline incomes $\left(P=C_{B}-G_{x}\right)$. Concluding, after the disaggregation of groups inequality increases and individual farms change their ranks to a certain extent compared to the implicit ranking of the grouped data approach. However, the distribution of absolute income losses with respect to baseline rankings $\left(C_{B}\right)$ is already well anticipated, on average, by the grouped data approach. This in turn leads to more regressive income changes in relative terms when individual data are applied mainly because the benchmark (the initial degree of inequality $G_{x}$ ) has changed.

The most remarkable difference occurs among the relative index of progressivity in the No_Pricepol scenario. It is remarkable not because of the scope of the difference but because of the qualitative interpretation. The analysis of between-groups inequality suggests an almost neutral distribution of 
income reductions in relative terms. Contrarily, the analysis of individual data shows a clear negative index which implies regressively distributed income losses.

However, large differences in the relative analysis, especially between the overall redistributive effects, should be interpreted with caution due to a high share of negative incomes in the analysis ( $26 \%$ of groups in Full_Lib have negative income and 36\% of individuals in the same scenario; for the baseline the ratio is $5 \%$ to $13 \%$ ). Even though the relative Gini is well defined in such cases, the difference between the relative Gini index of the baseline and the relative Gini of the scenarios (i.e. $R$ ) may suggest a strong disparity between the approaches which might as such not appear without the appearance of negative incomes since the relative Gini reacts more sensitive to the same changes in absolute distances (i.e. the numerator of the relative Gini) with lower mean incomes.

In Figure 2 relative Lorenz curves are presented for individual data of the baseline and all scenarios to illustrate the impact of negative values and at the same time demonstrate that the Gini based inequality analysis in Table 1 ranks distributions appropriately.

Figure 2: Relative Lorenz curves for baseline and all scenarios

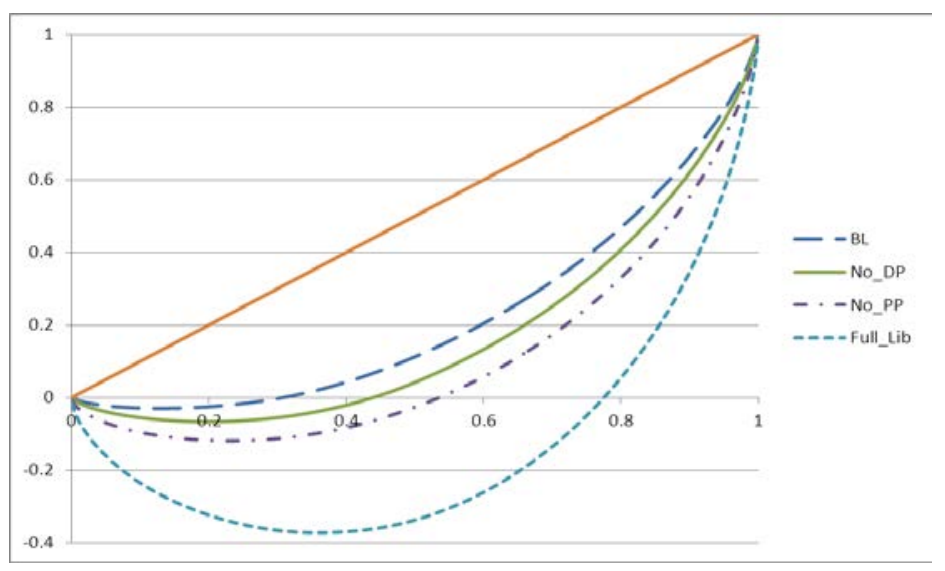

Source: Own calculations.

In comparison, two other studies conducting a similar approach to account for the impacts of grouping denote much stronger impacts on the qualitative results. Bourguignon et al. (2005) combine a standard multisector CGE model with a behavioural micro-simulation model to account for changes in real income under different real devaluation scenarios for Indonesia. They contrast resulting inequality changes based on ten groups with constant within-group inequality with results based on disaggregated incomes of 9,800 individual households. Their results indicate substantial differences between the two methodologies and they found sign reversing effects due to the disaggregation. In a similar study Savard (2005) compares results based on seven representative household groups of a CGE model with results based on additionally disaggregated incomes for 39,520 households generated by a combination of a CGE and a microsimulation model. For a trade liberalisation scenario for the Philippines he finds that the two approaches systematically produce inverse results in the analysis of inequality effects at the national level (Savard, 2005). However, the two cited studies differ from the work at hand as they apply behavioural micro-models instead of accounting models for further disaggregation of the results but also much fewer and larger representative household groups in the aggregated model. Thus, the aggregation bias in the aggregated analysis probably is much more serious than in the analysis based on 467 farm groups including only 17 individual farms on average. Furthermore, they assume the observed distribution of 
incomes inside the representative groups to be constant, whereas in our study within-group inequality is assumed to be constantly zero for the group based analysis since we want to evaluate the performance of agricultural sector models in the analysis of redistributive effects which are already highly disaggregated but still do not operate at the single farm level.

\section{Conclusions}

Since the CAP has increasingly been justified in recent decades by contributing to farm income stability, it is important to evaluate redistributive effects resulting from this policy, with obvious policy relevance. In this paper, different CAP liberalization scenarios are analysed with respect to inequality impacts in the agricultural sector. A tool is developed for this purpose that is able to consistently assess impacts of agricultural sector policy on individual farm incomes in western Germany.

The results of this paper indicate that an abolishment of the main components of the CAP, direct payments and market and price policies, increases income inequality in the western German agricultural sector for all scenarios in relative terms but decreases inequality in absolute terms. On the one hand, increasing relative inequality implies that low-income farms tend to lose a higher share of their income compared to high-income farms when CAP instruments are abolished. On the other hand, however, a decreasing absolute inequality implies that high-income farms lose higher absolute amounts of income than small-income farms when the CAP is abolished. We conclude that if the CAP aims at a more equal income distribution within the agricultural sector, then significant scope for improving the design of respective policy instruments exists. Ideally the allocation of agricultural support should then be tied to income indicators instead of the current support criteria "production quantities" (for market price policies) or "land" (for DPs). This being said, there are good arguments that any sectoral agricultural income policy should not be attributed to the EU-level, but to the Member States of the EU (Grethe, 2008), and the CAP should instead solely focus on the provision of public goods such as environmental externalities or animal welfare (WBA, 2005), a discussion which is beyond the scope of this paper.

Comparing the inequality analysis based on individual data with an analysis of grouped data reveals that the level of inequality may be seriously underestimated when only taking grouped data into account. Redistributive effects from scenario analysis differ slightly in absolute terms and more in relative terms. Yet, the differences in the relative analysis should be interpreted with caution due to the appearance of negative incomes in the sample. In none of the scenarios does the use of individual instead of grouped data lead to sign inversion of any of the inequality indicators.

A caveat of our methodology clearly is that the micromodel which disaggregates farm groups is static and relies on the behavioural changes of the groups of the meso-model, which are mapped accordingly. Nevertheless, heterogeneity among production patterns of farms in the same group is taken into consideration because different production patterns and factor endowments of individual farms are accounted for. Furthermore, with an average group aggregating just 17 FADN farms and stratification undertaken according to type, region, and size, the assumption of similar behaviour of individual farms belonging to the same group seems defendable. In general, the tool enables a substantially more specific analysis of inequality effects compared to an analysis of grouped data. 


\section{References}

Agra-Europe (2013). Report reveals ‘inequality’ with CAP direct payments, in: Agra-Europe, No. 2559, April 2nd, 2013, p.3.

Allanson, P. (2006). The Redistributive Effects of Agricultural Policy on Scottish Farm Incomes, Journal of Agricultural Economics 57, 117-128.

Allanson, P. (2008). On the Characterisation and Measurement of the Redistributive Effect of Agricultural Policy, Journal of Agricultural Economics, 59, 169-187.

Allanson, P. and Petrie, D. (2012). On the Choice of Health Inequality Measure for the Longitudinal Analysis of Income-Related Health Inequalities. Health Economics 22, 353-365.

Amiel, Y., Cowell, F. \& Polovin, A., (1996). Inequality among the Kibbutzim. Economica, 63, S63-S85.

Aronson, J.R., Johnson, P. \& Lambert, P.J. (1994). Redistributive Effects and Unequal Income Tax Treatment. Economic Journal, 104, 262-70.

Atkinson, A. B. (1980). Horizontal Equity and the Distribution of Tax Burden. In: Aaron, H.J. \& Boskin, M.J. (eds.), The Economics of taxation, Brookings Institution Press, 3-18.

Bertelsmeier, M. (2005). Analyse der Wirkungen unterschiedlicher Systeme von direkten Transferzahlungen unter besonderer Berücksichtigung von Bodenpacht- und Quotenmärkten. Schriftenreihe des Bundesministeriums für Ernährung, Landwirtschaft und Forsten: Angewandte Wissenschaft 510.

Bourguignon, F., Bussolo, M. \& Pereira da Silva, L. (eds.). (2008), The Impact of Macroeconomic Policies on Poverty and Income Distribution, The World Bank, Oxford University Press, New York.

Bourguignon, F., Robilliard, A. \& Robinson, S., (2005). Representative versus Real Households in the Macroeconomic Modeling of Inequality, in: Kehoe, T.J., Srinivasan, T.N., Whalley, J. (eds.), Frontiers in Applied General Equilibrium Modeling, Cambridge University Press, 219-254.

Bourguignon, F. \& Ferreira, F.H.G. (2003). Ex Ante Evaluation of Policy Reforms Using Behavioural Models, in: Bourguignon, F. \& Pereira da Silva, L. (eds.), The Impact of Economic Policies on Poverty and Income Distribution - Evaluation Techniques and Tools, The World Bank and Oxford University Press, 123-141.

Chakravarty, S. R. (1990). Ethical social index numbers. Springer, Berlin.

Chen, C.-N., Tsaur, T.-W. \& Rhai, T.-S. (1982). The Gini Coefficient and Negative Income. Oxford Economic Papers, 34, 473-478.

Cororaton, C.B. \& Cockburn, J. (2007). Trade reform and poverty-Lessons from the Philippines: A CGE-microsimulation analysis. Journal of Policy Modeling 29, 141-163. doi:10.1016/j.jpolmod.2006.07.006.

Cowell, F. A. (2009). Measuring Inequality, Oxford University Press.

Day, R.H. (1963). On Aggregating Linear Programming Models of Production. Journal of Farm Economics, 45, 797-813.

Debowicz, D. \& Golan, J. (2014). The impact of Oportunidades on human capital and income distribution in Mexico: A top-down/bottom-up approach. Journal of Policy Modeling 36, 24-42. doi:10.1016/j.jpolmod.2013.10.014.

Deppermann. A., Grethe, H. \& Offermann, F. (2010). Farm Level Effects of EU Policy Liberalization: Simulations Based on an EU-Wide Agricultural Sector Model and a Supply Model of the German Agricultural Sector, Contributed Paper at the 114th EAAE Seminar "Structural Change in Agriculture", Berlin, April 2010. http://purl.umn.edu/61083.

Deppermann, A., Grethe, H. \& Offermann, F. (2014). Distributional effects of CAP liberalisation on western German farm incomes: an ex-ante analysis. European Review of Agricultural Economics, doi: 10.1093/erae/jbt034. 
Deutsch, J. \& Silber, J., (1999). Inequality decomposition by population subgroups and the analysis of interdistributional inequality, in: Silber, S. (ed.) Handbook of Income Inequality Measurement. Springer, 363-403.

El Benni, N. \& Finger, R., (2013). The effect of agricultural policy reforms on income inequality in Swiss agriculture - An analysis for valley, hill and mountain regions. Journal of Policy Modeling, 35, 638651.

European Commission (2012). Report on the distribution of direct aids to agricultural producers (financial year 2011); http://ec.europa.eu/agriculture/cap-funding/beneficiaries/direct-aid/index_en.htm.[accessed 26.05.2013].

FAPRI (2011). U.S. and World Agricultural Outlook, http://www.fapri.iastate.edu/outlook/2011/ [accessed 05.12.2012].

Gocht, A., Britz, W., Ciaian, P. \& Paloma, S.G. (2013), Farm Type Effects of an EU-wide Direct Payment Harmonisation. Journal of Agricultural Economics 64, 1-32.

Grethe, H. (2008). Agriculture Policy: What Roles for the EU and the Member States? In: Gelauff, G., Grilo, I. and A. Lejour (eds.), Subsidiarity and Economic Reform in Europe. Springer, 191-218.

Grethe, H. (ed.) (2012). European Simulation Model (ESIM): Documentation (Model Code, Parameterization, Database). December 11, Hohenheim.

Hazell P.B.R. \& Norton, R.D. (1986). Mathematical Programing for Economic Analysis in Agriculture. New York: MacMillan.

Hertel, T.W., Keeney, R., Ivanic, M. \& Winters, L.A. (2007), Distributional effects of WTO agricultural reforms in rich and poor countries. Economic Policy 22, 289-337.

Kakwani, N. (1977). Measurement of Tax Progressivity: An International Comparison. The Economic Journal, 87, 71-80.

Kakwani, N. (1986). Analyzing redistribution policies - a study using Australian data, Cambridge University Press.

Keeney, M. (2000). The distributional impact of direct payments on Irish farm incomes. Journal of Agricultural Economics, 51, 252-265.

Keeney, R. (2009), Transfer Efficiency and Distributional Impacts of U.S. Farm Support: Evidence from a Macro-Micro Simulation. American Journal of Agricultural Economics, 91, 1289-1295.

Keeney, R. \& Beckman, J. (2009), WTO negotiations on agriculture and the distributional impacts for US rice farm households. Food Policy 34, 70-80.

Lambert, P.J. (2001). The distribution and redistribution of income. Manchester University Press.

Louhichi, K. \& Valin, H. (2012). Impact of EU biofuel policies on the French arable sector: A microlevel analysis using global market and farm-based supply models. Review of Agricultural and Environmental Studies, 93, 233-272.

Mishra, A., El-Osta, H. \& Gillespie, J.M. (2009). Effect of agricultural policy on regional income inequality among farm households. Journal of Policy Modeling, 31, 325-340.

Moreddu, C. (2011). Distribution of Support and Income in Agriculture, OECD Food, Agriculture and Fisheries Papers, No. 46, OECD Publishing. http://dx.doi.org/10.1787/5kgch21wkmbx-en.

Mussard, S. \& Savard, L., (2010), Macro/Micro-Economic Modelling and Gini Multi-Decomposition: An Application to the Philippines. Journal of Income Distribution, 19, 51-78.

Offermann, F., Kleinhanß, W., Hüttel, S. \& Küpker, B. (2005). Assessing the 2003 CAP Reform Impacts on German Agriculture Using the Farm Group Model FARMIS. In Arfini, F. (ed.) Modelling Agricultural Policies: State of the Art and New Challenges. Proceedings of the 89th European Seminar of the EAAE, Parma, Italy, February 3-5, 2005. Parma: Monte Universita Parma Editore: 546-564.

Offermann,F. (2008). Key issues of linking models for policy impact assessment in agriculture. German Journal of Agricultural Economics , 57, 361-162. 
Osterburg, B., Offermann, F. \& Kleinhanß, W. (2001). A Sector Consistent Farm Group Model for German Agriculture. In: Heckelei, T., Witzke, H.P. \& Henrichsmeyer, W. (eds.): Agricultural Sector Modelling and Policy Information Systems. Verlag Vauk Kiel: 152-160.

Plotnick, R. (1981). A Measure of Horizontal Inequity. The Review of Economics and Statistics, 63, 283288.

Pyatt, G. (1976). On the Interpretation and Disaggregation of Gini Coefficients. The Economic Journal, 86, 243-255.

Savard, L., (2005). Poverty and Inequality Analysis within a CGE Framework: A Comparative Analysis of the Representative Agent and Microsimulation Approaches. Development Policy Review, 23, 313331.

Severini, S. \& Tantari, A. (2015). The distributional impact of agricultural policy tools on Italian farm household incomes. Journal of Policy Modeling 37, 124-135. doi:10.1016/j.jpolmod.2015.01.004.

Severini, S. \& Tantari, A., (2013). The impact of agricultural policy on farm income concentration: the case of regional implementation of the CAP direct payments in Italy. Agricultural Economics 44, 275286.

Shorrocks, A. \& Wan, G. (2005). Spatial decomposition of inequality. Journal of Economic Geography 5, 59-81.

The new Statesman (2012). http://www.newstatesman.com/politics/politics/2012/09/aid-aristocrats, [accessed 13.06.2013].

Van Tongeren, F. (2000). Perspectives on Modelling EU Agricultural Policies, German Journal of Agricultural Economics 49, 157-163.

WBA (Wissenschaftlicher Beirat Agrarpolitik, nachhaltige Landbewirtschaftung und Entwicklung ländlicher Räume Beim Bundesministerium für Verbraucherschutz und Landwirtschaft) (2005). Stellungnahme zum Vorschlag für die ELER-Verordnung, KOM(2004)490, Berichte über Landwirtschaft, 83.

Woltjer, G., Bezlepkina, I., van Leeuwen, M., Helming, J., Bunte, F., Buisman, E., Luesink, H., Kruseman, G., Polman, N., van der Veen, H. \& Verwaart, T. (2011). The agricultural world in equations; An overview of the main models used at LEI, LEI Memorandum 11-151. 